\title{
Systematic Review and Meta-Analysis of Preoperative Antisepsis with Combination Chlorhexidine and Povidone-lodine
}

\author{
Benjamin M. Davies ${ }^{1}$ Hiren C. Patel ${ }^{1}$ \\ ${ }^{1}$ Department of Neurosurgery, Greater Manchester Neuroscience \\ Centre, Salford Royal Foundation Trust (SRFT), Salford, \\ United Kingdom
}

Surg J 2016;2:e70-e77.

\begin{abstract}
Address for correspondence Benjamin M. Davies, MRCS, Department of Neurosurgery, Greater Manchester Neuroscience Centre, Salford Royal Foundation Trust (SRFT), Stott Lane, Salford M6 8HD, United Kingdom (e-mail: Benjamin.davies4@nhs.net).
\end{abstract}

\begin{abstract}
\section{Keywords}

- surgical site infection

- surgical wound infection

- antisepsis

- chlorhexidine

- povidone-iodine
\end{abstract}

Importance Effective preoperative antisepsis is recognized to prevent surgical site infection (SSI), although the definitive method is unclear. Many have compared chlorhexidine ( $\mathrm{CHG}$ ) with povidone-iodine (PVI), but there is emerging evidence for combination usage.

Objective To conduct a systematic review and meta-analysis to evaluate if combination skin preparation (1) reduces colonization at the operative site and (2) prevents SSI compared with single-agent use.

Data Sources A literature search of MEDLINE, Embase, and Cochrane Database of Clinical Trials was performed.

Study Selection Comparative, human trials considering the combination use of CHG and $\mathrm{PVI}$, as preoperative antisepsis, to single-agent $\mathrm{CHG}$ or PVI use were included. Studies were excluded from meta-analysis if the use or absence of alcohol was inconsistent between study arms.

Data Extraction and Synthesis The study was performed using PRISMA (Preferred Reporting Items for Systematic Reviews and Meta-Analyses) guidelines.

Main Outcomes and Measures The primary outcome for meta-analysis was surgical site infection. The secondary outcome was colonization at the operative site.

Results Eighteen publications with a combination of $\mathrm{CHG}$ and PVI use were identified. Of these, 12/14 inferred promise for combination usage, including four trials eligible for meta-analysis. Only one trial reported SSI as its outcome. The remaining three considered bacterial colonization. Combination preparation had a pooled odds ratio for complete decolonization of 5.62 (95\% confidence interval 3.2 to $9.7, p<0.00001$ ). There was no evidence of heterogeneity (Cochran's $Q 2.1,2 d f, p=0.35$ ).

Conclusions and Relevance There is emerging, albeit low-quality, evidence in favor of combination $\mathrm{CHG}$ and PVI preoperative antisepsis. Further rigorous investigation is indicated.
Surgical site infection (SSI) is a significant cause of postoperative morbidity and mortality, increasing length of hospital stay and cost of care. ${ }^{1-3}$ SSIs are the second most common cause of health care associated infection; U.S. studies have estimated a $\$ 45$ billion annual cost. ${ }^{4}$

received

January 31, 2016 accepted after revision July 12,2016
DOI http://dx.doi.org/ $10.1055 / \mathrm{s}-0036-1587691$. ISSN 2378-5128.
Since Joseph Lister popularized the role of preoperative antisepsis in the 1800 s, attempts to identify the optimal process and/or agent have resulted in several trials and much scientific tribulation. ${ }^{5}$ Despite this effort, no absolute has emerged; a good example is the efforts to identify which
Copyright $\odot 2016$ by Thieme Medical Publishers, Inc., 333 Seventh Avenue, New York, NY 10001, USA. Tel: +1(212) 584-4662.
License terms

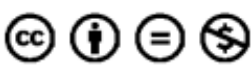


of chlorhexidine (CHG) or povidone-iodine (PVI) is more effective. Several meta-analyses have been published, with no comprehensive conclusion in favor of one or the other. ${ }^{6-10}$

CHG and PVI have different mechanisms of action and different spectrums of efficacy. Their simultaneous application was thought to form a less effective cocktail, although this belief has recently been challenged in vitro, with evidence in fact for a potential synergistic effect. ${ }^{11}$ Regardless, sequential application would circumvent such concerns.

In clinical practice, therefore, no single chemical containing both CHG and PVI has been available. However, perhaps following the logic that "more is less" or covering all bases in the debate of CHG versus PVI, anecdotally and despite little scientific study of the method, many surgeons use a combination of CHG preparation and PVI preparation in sequence.

Our objectives therefore were to perform a systematic review and meta-analysis to consider the evidence for combination CHG and PVI antisepsis. Specifically, we aimed to study if combination skin preparation (1) reduces SSI compared with single-agent use and (2) reduces colonization at the operative site.

\section{Methods}

\section{Systematic Review}

MEDLINE (Ovid), Embase (Ovid), and Cochrane database of clinical trials (Ovid) were searched on April 1, 2015, using the search strategy ("Surgical site infection" OR "Surgical Wound Infection") AND ("Chlorhexidine") AND ("Iodine" OR "Iodine Compounds" OR "Povidone-Iodine" OR "Idophor") adapted from Dumville et al. ${ }^{6}$

A single reviewer screened resulting abstracts to select studies where a combination of CHG and PVI had been used. If unclear from the abstract alone, the full publication was sought. References from the short-listed abstracts were additionally screened for relevant studies. A second reviewer then rechecked this short list. Their quality of evidence was assessed by each reviewer independently and graded using the Oxford Levels of Evidence criteria. ${ }^{12}$ Any disagreement was resolved by common discussion.

\section{Meta-Analysis}

The primary outcome for the meta-analysis was SSI. The secondary outcome was decolonization at the operative site. For the meta-analysis, comparative, human trials comparing the use of combination CHG and PVI, as preoperative (i.e., just prior to incision) antisepsis, to singleagent $\mathrm{CHG}$ or PVI use were included. Studies were excluded if the use or absence of alcohol was inconsistent between arms of the study. Two reviewers assessed eligibility independently and any disagreement was resolved through discussion and mutual agreement. Assessment of bias was also conducted by each reviewer independently, using the criteria set out by Higgins et al. ${ }^{13}$ This information was analyzed in combination with the GRADE profiling method, using GRADEpro (Evidence Prime, Hamilton, Ontario, Canada) to assess the overall quality of evidence relating to our primary and secondary outcomes. ${ }^{14}$
Pooled analysis was conducted using Revman V5.3 (Cochrane Collaborative, Copenhagen, Denmark). Study heterogeneity was assessed using the Cochrane $\mathrm{Q}$ test, where $p<0.05$ indicated significant heterogeneity and pooled odds ratios (ORs), with $95 \%$ confidence intervals (Cls), were calculated to assess overall effect.

\section{Results}

A PRISMA (Preferred Reporting Items for Systematic Reviews and Meta-Analyses) flow diagram for our search methodology and results is presented in -Fig. 1. This strategy identified 18 publications where a combination of CHG and PVI had been used ( - Table 1). ${ }^{1,11,15-30}$ Only four of these publications were eligible for the meta-analysis. ${ }^{24-26,30}$

Of the excluded but short-listed studies, 12/14 offered some indication of a role for combination $\mathrm{CHG}$ and PVI skin preparation, including 3 studies detailing the implementation of a bundle of care requiring combination skin preparation, ${ }^{16,22,23} 1$ letter in favor of its use, ${ }^{20} 5$ clinical trials where combination skin preparation was standard practice in both arms, ${ }^{17,19,27-29} 1$ trial in favor of combination CHG and PVI for preoperative nasal decolonisation, ${ }^{21} 1$ trial in favor for central line insertion, ${ }^{1}$ and 1 basic science study. ${ }^{11}$ Only 1 study suggested the combination provided no additional benefit. ${ }^{18}$ These publications were considered level 5 evidence.

\section{Primary Objective: Does Combination Skin Preparation Reduce Surgical Site Infection Rates?}

Only 1 of the 4 eligible studies reported SSI as the outcome. This study was a conference abstract of a randomized controlled trial (RCT) of 1,404 women undergoing cesarean section to preoperative antisepsis with PVI, CHG, or combination CHG and PVI by Ngai et al. ${ }^{26}$ During analysis, the article was subsequently published in full. ${ }^{31}$ The study identified SSI incidences of $4.6 \% \mathrm{PVI}, 4.5 \% \mathrm{CHG}$, and $3.9 \% \mathrm{CHG}$ and PVI. This difference was not significant. However, on performing subgroup analysis of class III obese women, a combination of $\mathrm{CHG}$ and PVI was demonstrated to reduce SSI in a multivariate model (OR 0.17, Cl 0.04 to 0.77 ).

\section{Secondary Objective: Does Combination Skin Preparation Reduce Bacterial Colonization at the Operative Site?}

The remaining three studies reported bacterial colonization as their outcome. ${ }^{24,25,30}$ The quality of evidence had a moderate to high risk of bias, given the methodologies were susceptible to selection, performance, and detection bias (-Fig. 2). Specific discrepancies included the tissue choice (grafted skin tissue, ${ }^{25}$ regular skin, ${ }^{24}$ and the umbilicus ${ }^{30}$ ), the application (CHG/alcohol/PVI, ${ }^{25} \mathrm{CHG} / \mathrm{PVI} / \mathrm{PVI},{ }^{24}$ and $\mathrm{PVI}-$ soaked sponge for 1 hour/CHG with alcohol ${ }^{30}$ ), and the control preparation (-Table 2 ).

In addition, it was often unclear as to whether adequate precautions had been taken to neutralize the samples during bacterial counting.

The outcomes of these studies also differed, but they all reported the proportion of individual patients yielding no 


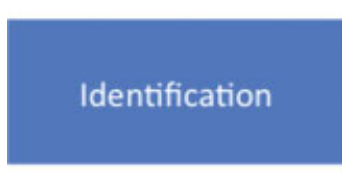

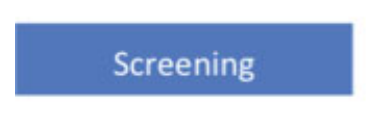

\section{Publications identified}

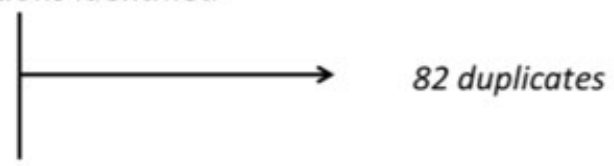

183 potentially relevant publications

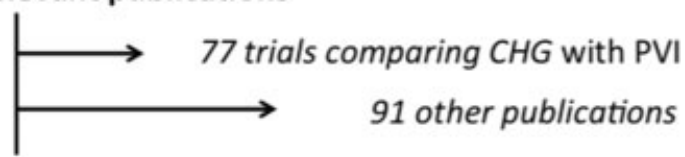

15 publications using combination $\mathrm{CHG}$ and $\mathrm{PVI}$

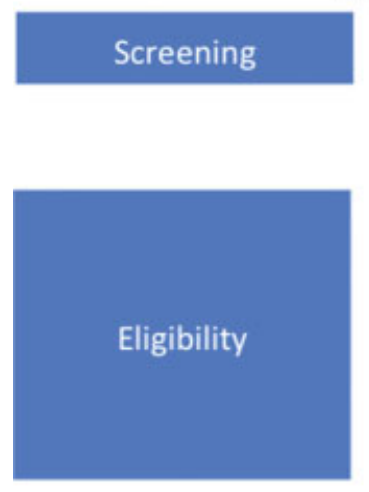

\author{
3 additional \\ publications
}

18 potentially eligible publications

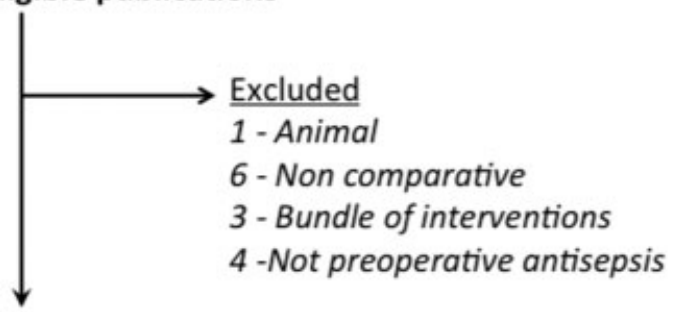

4 studies eligible for meta-analysis

Fig. 1 PRISMA (Preferred Reporting Items for Systematic Reviews and Meta-Analyses) flow diagram of search strategy. Abbreviations: CHG, chlorhexidine; PVI, povidone-iodine.

growth. Overall, therefore the result for 547 patients could be pooled for analysis.

Complete decolonization rates were greatest for combination CHG and PVI (90\%), compared with CHG (65\%) or PVI (47\%) alone, and yielded a pooled OR for complete decolonization of 5.62 (95\% CI 3.2 to 9.7, $p<0.00001$ ) in favor of combination CHG and PVI skin preparation (-Fig. 3). There was no evidence of heterogeneity (Cochran's Q 2.1, $2 d f$, $p=0.35$ ).

\section{Discussion}

At present, only a single high-quality RCT has considered the effect of a combination of CHG and PVI with some promise. The evidence for improved bacterial decolonization with a combination of PVI and CHG is perhaps firmer.

Although a reduction in SSI is a logical result of greater bacterial decolonization, studies have reported contradicting examples. ${ }^{32,33}$ The relative infrequency of SSI has led to the acceptance of surrogate markers such as skin cultures, ${ }^{34}$ but their association with SSI is not well validated. ${ }^{7}$ As a multifactorial problem, it is likely that the effect was hidden, but it poses a hurdle for future investigation. ${ }^{34}$

This difficulty can be seen in the RCT by Ngai et al. ${ }^{31}$ During their study, they found an unexpected low incidence of SSI, which resulted in an underpowered study. Post hoc analysis suggested a sample size of 3,000 would have been required to detect a significant difference. ${ }^{31}$ Although such a large-scale study would be unusual in surgery, the requirement for improved methods of combatting SSI is clear. SSI significantly contributes to postoperative morbidity and mortality, and with worsening antibiotic resistance, it could become more pertinent. Powering to detect a $0.5 \%$ improvement therefore has major implications, when its extrapolation across different fields of surgery all around the globe is considered.

An additional question to be answered is whether the efficacy of combination skin preparation draws on the intrinsic requirement for the skin to be cleaned twice rather than the agent itself. There is some evidence to suggest this factor is not significant: May et al controlled for this eventuality when comparing PVI with CHG and PVI, ${ }^{25}$ and O'Shaughnessy et al and Langgartner et al found the decolonization effect of $\mathrm{CHG}$ is not time-dependent. ${ }^{1,35}$ However, Morrison et al, using iodine and alcohol, found double preparation more effective. ${ }^{36}$

Placing our findings within the existing body of literature is difficult, given its paucity. The pooled analysis identified that PVI was less effective than $\mathrm{CHG}$, which reassuringly is in keeping with consensus from the literature. ${ }^{6,8}$ Additionally, the greater efficacy of combination CHG and PVI mirrors findings from other types of antisepsis and its incorporation into successful bundles of perioperative care. ${ }^{1,16,22,23}$

On the background of our findings from this systematic review, we have conducted a retrospective assessment of our neurosurgical surveillance data from a single center. ${ }^{37}$ In a multivariate model, we identified a greater than fivefold benefit for combination CHG and PVI(OR 0.12, CI 0.02 to 0.63 ). 
Povidone-lodine with Chlorhexidine for Surgical Antisepsis Davies, Patel e73

\begin{tabular}{|c|c|c|c|c|c|c|c|c|c|c|}
\hline 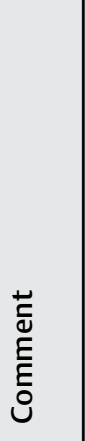 & 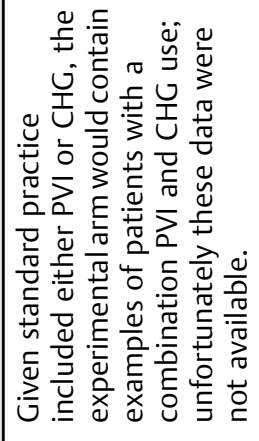 & 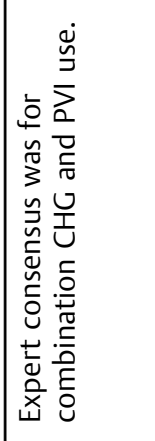 & 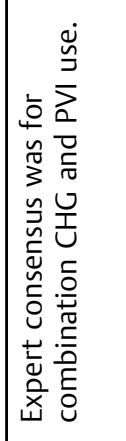 & 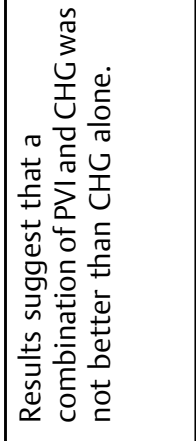 & 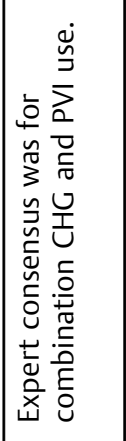 & 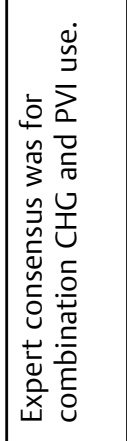 & 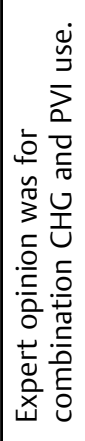 & 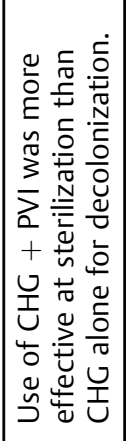 & 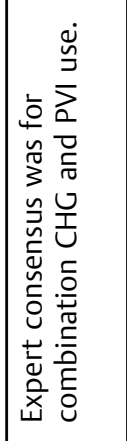 & 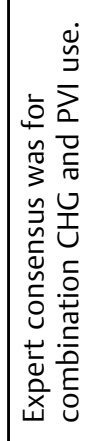 \\
\hline 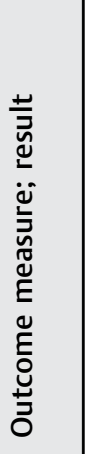 & 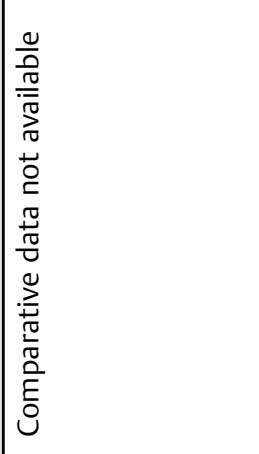 & 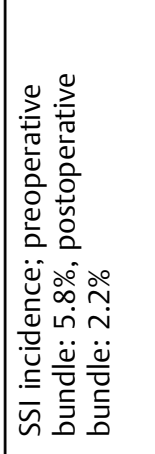 & 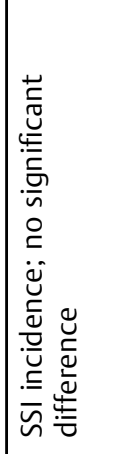 & 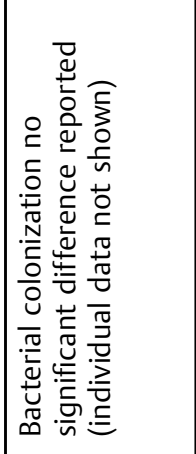 & 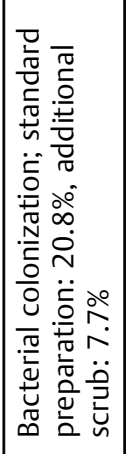 & 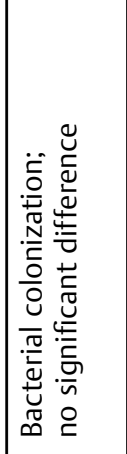 & $\frac{\pi}{z}$ & 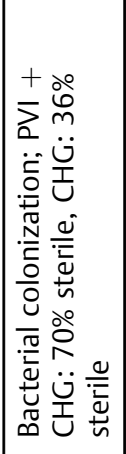 & 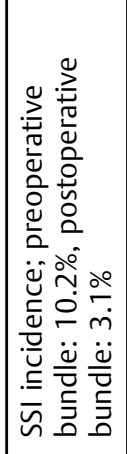 & 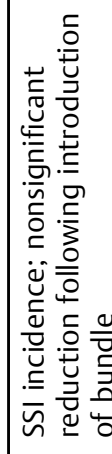 \\
\hline 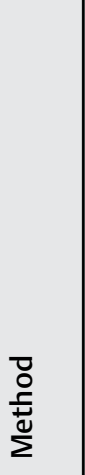 & 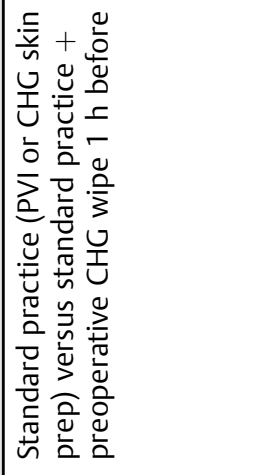 & 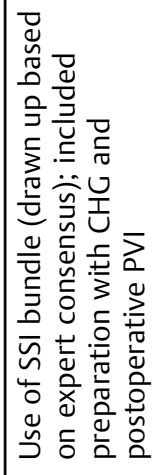 & 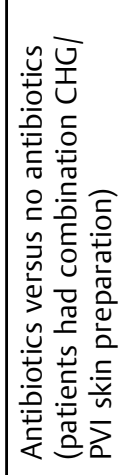 & 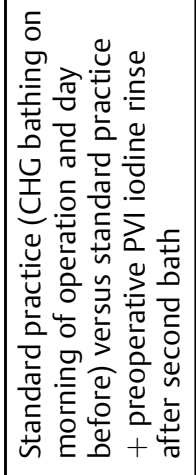 & 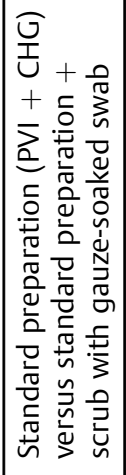 & 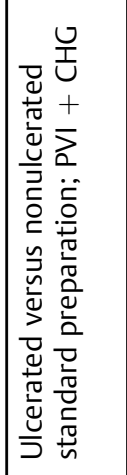 & $\frac{\Sigma}{z}$ & 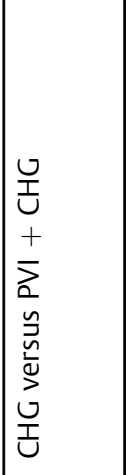 & 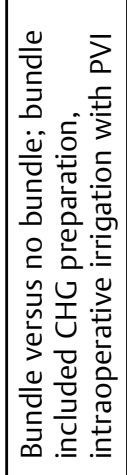 & 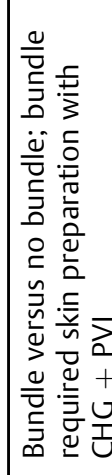 \\
\hline 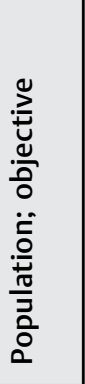 & 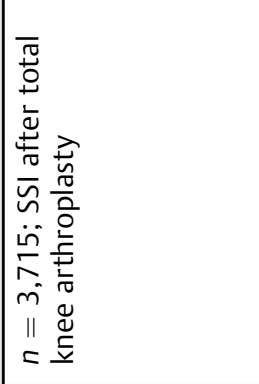 & 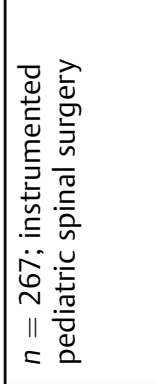 & 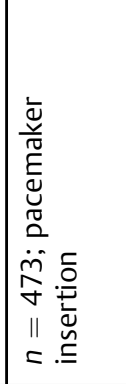 & 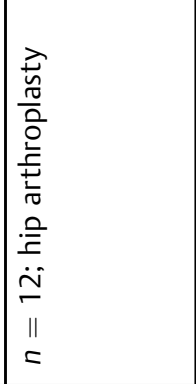 & 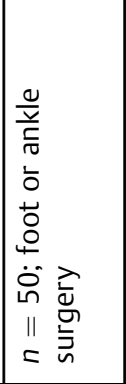 & 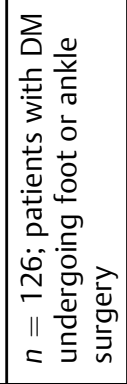 & 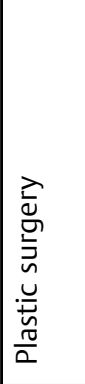 & 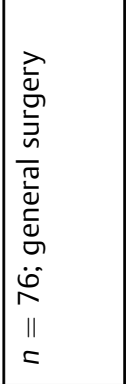 & 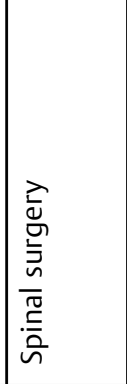 & 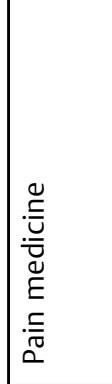 \\
\hline 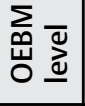 & $\frac{\ll}{z}$ & $\nabla$ & in & in & in & เn & in & in & เn & In \\
\hline 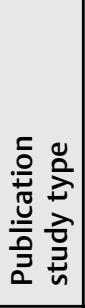 & 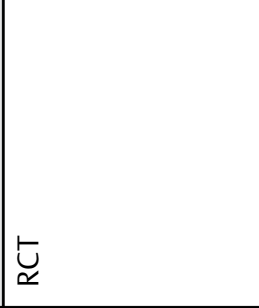 & 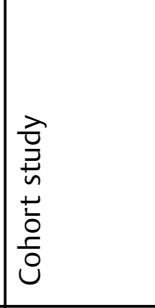 & $\underset{\longleftarrow}{\longleftarrow}$ & 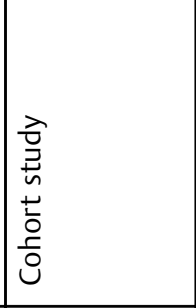 & $\underset{\longleftarrow}{\longleftarrow}$ & 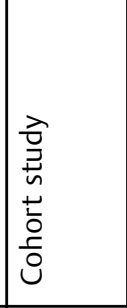 & 离 & 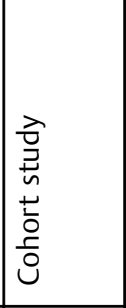 & 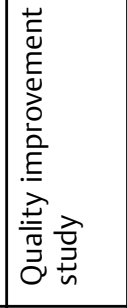 & 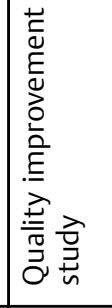 \\
\hline 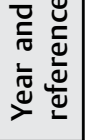 & 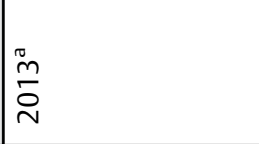 & 竞 & ‡ু & \begin{tabular}{l}
0 \\
$\stackrel{0}{\circ}$ \\
\hdashline
\end{tabular} & స్ & i & $\stackrel{N}{\tilde{N}}$ & 㐭 & $\stackrel{m}{\stackrel{m}{\nu}}$ & 會 \\
\hline
\end{tabular}




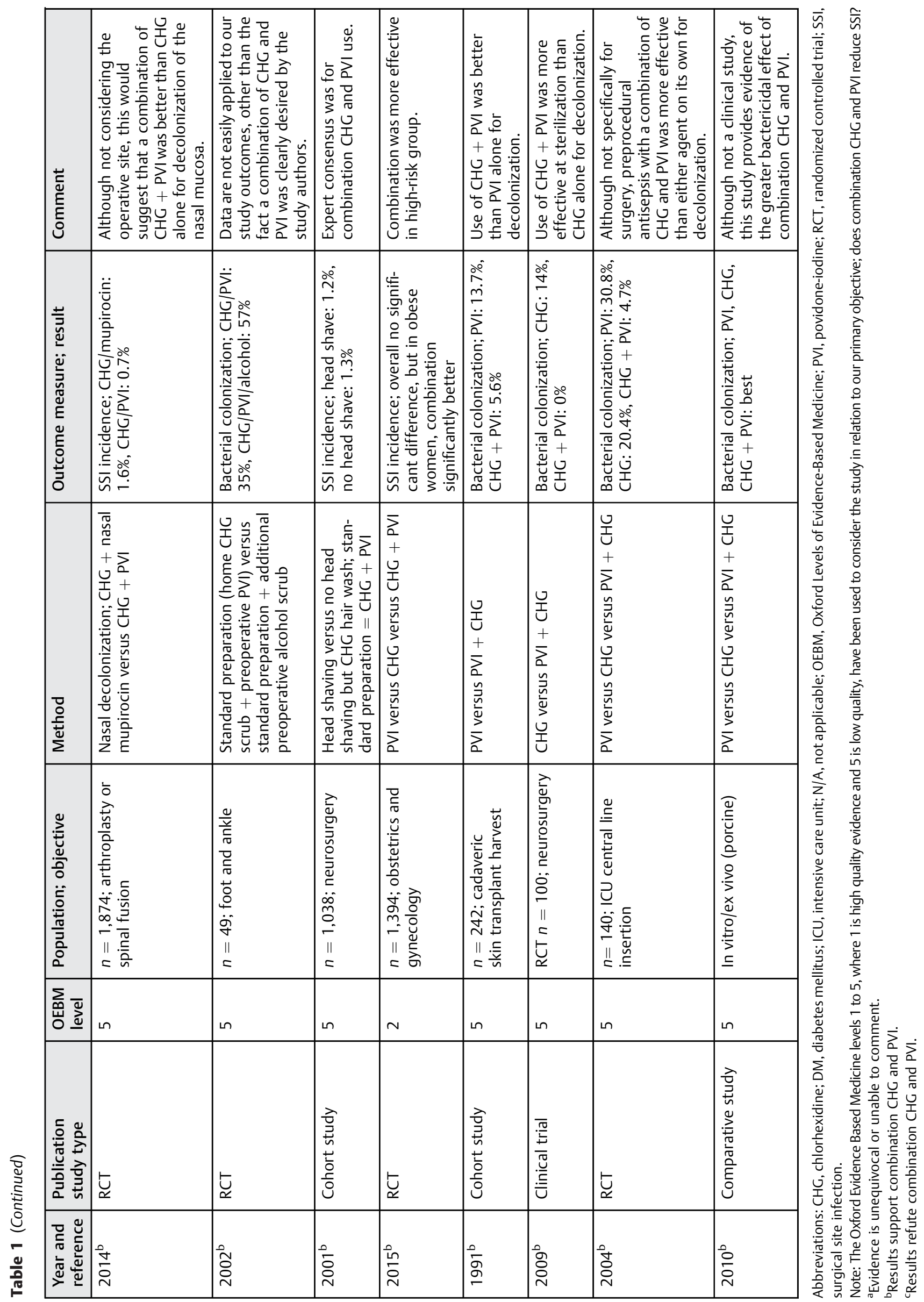


A

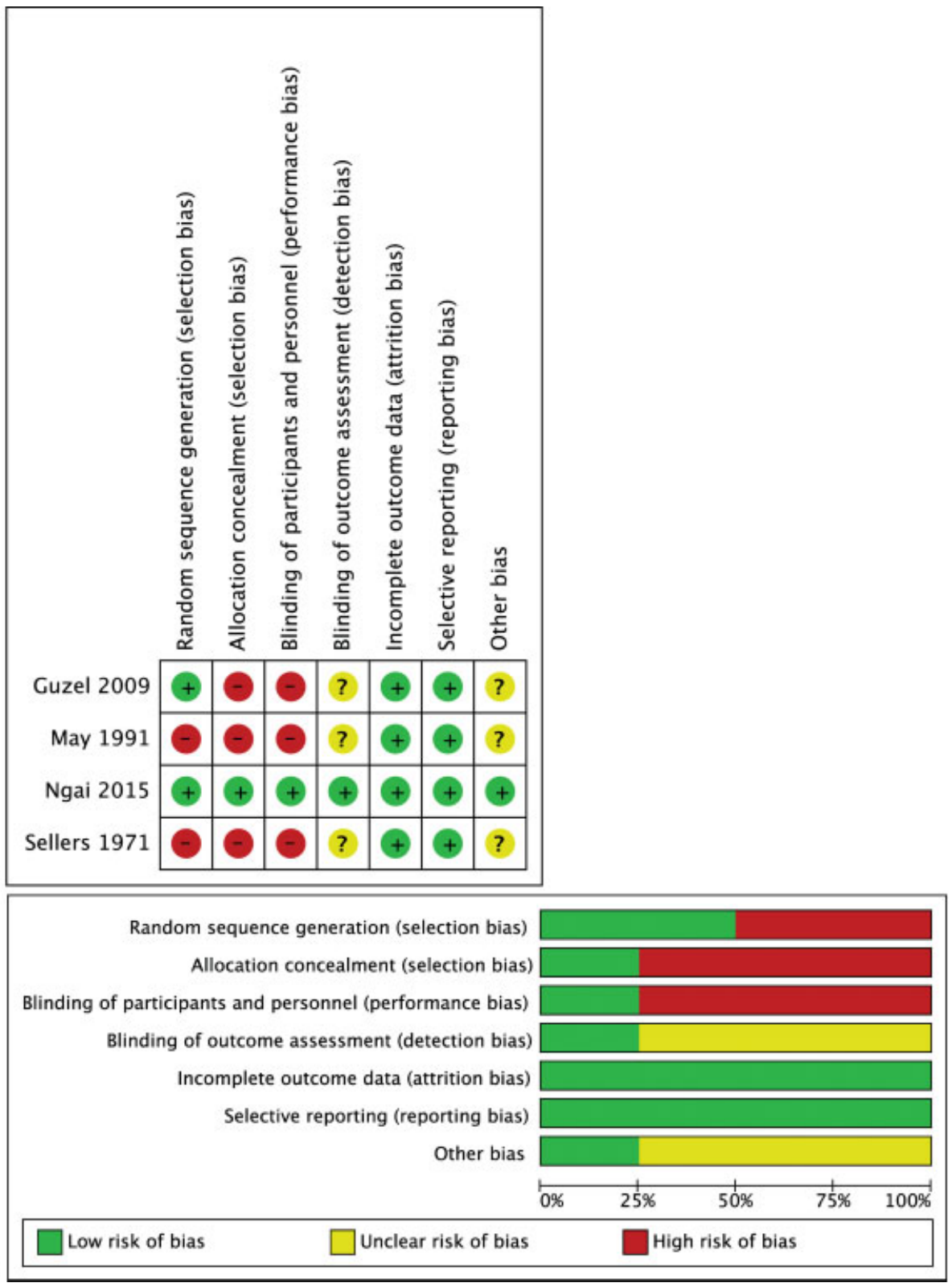

Fig. 2 Risk of bias summary (A) and graph (B) for studies eligible for meta-analysis.

Table 2 Comparison of the study design and methodology for those studies included in a meta-analysis of bacterial decolonization

\begin{tabular}{|l|l|l|l|}
\hline & Sellers and Newman & May et al ${ }^{25}$ & Guzel et al $^{24}$ \\
\hline Tissue type & $\begin{array}{l}\text { Human umbilicus in abdominal } \\
\text { surgery }\end{array}$ & Harvested human skin grafts & $\begin{array}{l}\text { Neurosurgical operating site (cranial and } \\
\text { spinal) }\end{array}$ \\
\hline Sample & $\begin{array}{l}n=105 ; \text { patients were treated as } \\
\text { separate samples }\end{array}$ & $\begin{array}{l}n=342 ; \text { grafts were taken from multiple } \\
\text { sites, yielding 3,263 samples }\end{array}$ & $\begin{array}{l}n=100 ; \text { patients were treated as separate } \\
\text { samples; } 50 \text { cranial and } 50 \text { spinal patients }\end{array}$ \\
\hline Control arm & $n=70$ & $n=294(2,940$ samples) & N/A \\
\hline Combination arm & $n=35$ & $n=48(323$ samples $)$ & N/A \\
\hline $\begin{array}{l}\text { Application method } \\
\text { including timing } \\
\text { if specified) }\end{array}$ & $\begin{array}{l}\text { PVl-soaked sponge for 1 h, CHG } \\
\text { with alcohol }\end{array}$ & CHG; alcohol; PVI & CHG 3 min; PVI $30 \mathrm{s;} \mathrm{PVI} 30 \mathrm{~s}$ \\
\hline $\begin{array}{l}\text { Control antisepsis } \\
\text { CHG with alcohol }\end{array}$ & PVI with alcohol; PVI & $\begin{array}{l}\text { Samples for culture counts were taken in } \\
\text { between cleanings; therefore counts after } \\
\text { CHG only are compared with CHG and PVI }\end{array}$ \\
\hline
\end{tabular}

Abbreviations: CHG, chlorhexidine; DM, diabetes mellitus; N/A, not applicable; PVI, povidone-iodine. 


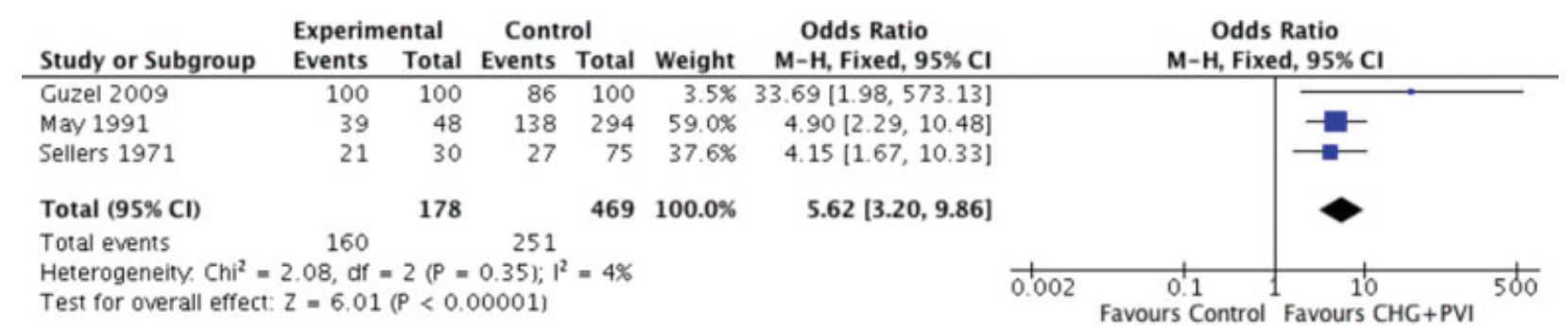

Fig. 3 Forrest plot showing the pooled effect of combination CHG and PVI on complete bacterial decolonization. Abbreviations: CHG, chlorhexidine; PVI, povidone-iodine.

Mechanistically, there is good reason to believe combination CHG and PVI would be of benefit. First, although both have a broad spectrum of antibacterial activity, PVI can also target viruses, fungi, and bacterial spores, and CHG can target yeast. Second, the action of PVI is intracellular, and therefore the action of CHG, which disrupts cell membranes, would theoretically augment its potency. And finally, PVI has a more immediate action than CHG, which is delayed. ${ }^{11,38}$

\section{Conclusion}

Further advances in the battle to prevent SSI are required as its significant impact is well recognized. Bacterial decolonization at the operative site is more effective when the combination is used. Although there is presently no level 1 evidence demonstrating a definitive effect of combination CHG and PVI for reducing SSI, building on promising mechanism-based reasoning, basic science data, and its incorporation into successful bundles of care, the use of combination CHG and PVI has shown promise in a large RCT. Further study is warranted.

\section{References}

1 Langgartner J, Linde HJ, Lehn N, Reng M, Schölmerich J, Glück T. Combined skin disinfection with chlorhexidine/propanol and aqueous povidone-iodine reduces bacterial colonisation of central venous catheters. Intensive Care Med 2004;30(6):1081-1088

2 Kirkland KB, Briggs JP, Trivette SL, Wilkinson WE, Sexton DJ. The impact of surgical-site infections in the 1990s: attributable mortality, excess length of hospitalization, and extra costs. Infect Control Hosp Epidemiol 1999;20(11):725-730

3 Coello R, Charlett A, Wilson J, Ward V, Pearson A, Borriello P. Adverse impact of surgical site infections in English hospitals. J Hosp Infect 2005;60(2):93-103

4 Thompson KM, Oldenburg WA, Deschamps C, Rupp WC, Smith CD. Chasing zero: the drive to eliminate surgical site infections. Ann Surg 2011;254(3):430-436, discussion 436-437

5 Lister J. On a new method of treating compound fracture, abscess, etc. Lancet 1867;89(2274):387-389

6 Dumville JC, McFarlane E, Edwards P, Lipp A, Holmes A. Preoperative skin antiseptics for preventing surgical wound infections after clean surgery. Cochrane Database Syst Rev 2013;3(3):CD003949

7 Lee I, Agarwal RK, Lee BY, Fishman NO, Umscheid CA. Systematic review and cost analysis comparing use of chlorhexidine with use of iodine for preoperative skin antisepsis to prevent surgical site infection. Infect Control Hosp Epidemiol 2010;31(12):1219-1229
8 Noorani A, Rabey N, Walsh SR, Davies RJ. Systematic review and meta-analysis of preoperative antisepsis with chlorhexidine versus povidone-iodine in clean-contaminated surgery. Br J Surg 2010;97(11):1614-1620

9 Haas DM, Morgan S, Contreras K. Vaginal preparation with antiseptic solution before cesarean section for preventing postoperative infections. Cochrane Database Syst Rev 2014; (12):CD007892

10 Hadiati DR, Hakimi M, Nurdiati DS, Ota E. Skin preparation for preventing infection following caesarean section. Cochrane Database Syst Rev 2014;(9):CD007462

11 Anderson MJ, Horn ME, Lin Y-C, Parks PJ, Peterson ML. Efficacy of concurrent application of chlorhexidine gluconate and povidone iodine against six nosocomial pathogens. Am J Infect Control 2010; 38(10):826-831

12 Oxford Centre for Evidence-Based Medicine. The Oxford Levels of Evidence 2. Available at: http://www.cebm.net/index.aspx?o=5653. Accessed May 30, 2015

13 Higgins JPT, Altman DG, Gøtzsche PC, et al; Cochrane Bias Methods Group; Cochrane Statistical Methods Group. The Cochrane Collaboration's tool for assessing risk of bias in randomised trials. BMJ 2011;343(2):d5928

14 Schünemann HJ. [GRADE: from grading the evidence to developing recommendations. A description of the system and a proposal regarding the transferability of the results of clinical research to clinical practice]. Z Evid Fortbild Qual Gesundhwes 2009;103(6): 391-400

15 Farber NJ, Chen AF, Bartsch SM, Feigel JL, Klatt BA. No infection reduction using chlorhexidine wipes in total joint arthroplasty. Clin Orthop Relat Res 2013;471(10):3120-3125

16 Ryan SL, Sen A, Staggers K, Luerssen TG, Jea A; Texas Children's Hospital Spine Study Group. A standardized protocol to reduce pediatric spine surgery infection: a quality improvement initiative. J Neurosurg Pediatr 2014;14(3):259-265

17 Mounsey JP, Griffith MJ, Tynan M, et al. Antibiotic prophylaxis in permanent pacemaker implantation: a prospective randomised trial. Br Heart J 1994;72(4):339-343

18 Haynes J, Leslie IJ, Speller DC. Are povidone-iodine compresses helpful in skin preparation for hip replacement surgery? J Hosp Infect 1986;7(1):96-98

19 Roukis TS. Bacterial skin contamination before and after surgical preparation of the foot, ankle, and lower leg in patients with diabetes and intact skin versus patients with diabetes and ulceration: a prospective controlled therapeutic study. J Foot Ankle Surg 2010;49(4):348-356

20 Mashhadi SA, Loh CYY. Combination of chlorhexidine gluconate and PVP in surgical site antisepsis. J Wound Care 2012;21; (3): 141

21 Phillips M, Rosenberg A, Shopsin B, et al. Preventing surgical site infections: a randomized, open-label trial of nasal mupirocin ointment and nasal povidone-iodine solution. Infect Control Hosp Epidemiol 2014;35(7):826-832 
22 Burgher $\mathrm{AH}$, Barnett $\mathrm{CF}$, Obray JB, Mauck WD. Introduction of infection control measures to reduce infection associated with implantable pain therapy devices. Pain Pract 2007;7(3):279-284

23 Murillo MG, Alvarez P, Gomilla CM, Sanchez-Mariscal F, Pizones L, Zuniga L. Influence of perioperative protocol to reduce postoperative infection rates in spine surgery. Preliminary study. Eur Spine J 2013;22(Suppl 5):125-137

24 Guzel A, Ozekinci T, Ozkan U, Celik Y, Ceviz A, Belen D. Evaluation of the skin flora after chlorhexidine and povidone-iodine preparation in neurosurgical practice. Surg Neurol 2009;71(2):207-210

25 May SR, Roberts DP, DeClement FA, Still JM Jr. Reduced bacteria on transplantable allograft skin after preparation with chlorhexidine gluconate, povidone-iodine, and isopropanol. J Burn Care Rehabil 1991;12(3):224-228

26 Ngai IM, Van Arsdale A, Govindappagari S, et al. Skin preparation for prevention of surgical site infection after cesarean delivery: a randomized controlled trial. Obstet Gynecol 2015;126(6): 1251-1257

27 Hort KR, DeOrio JK. Residual bacterial contamination after surgical preparation of the foot or ankle with or without alcohol. Foot Ankle Int 2002;23(10):946-948

28 Bekar A, Korfali E, Doğan S, Yilmazlar S, Başkan Z, Aksoy K. The effect of hair on infection after cranial surgery. Acta Neurochir (Wien) 2001;143(6):533-536, discussion 537

29 Brooks RA, Hollinghurst D, Ribbans WJ, Severn M. Bacterial recolonization during foot surgery: a prospective randomized study of toe preparation techniques. Foot Ankle Int 2001;22; (4):347-350
30 Sellers J, Newman JH. Disinfection of the umbilicus for abdominal surgery. Lancet 1971;2(7737):1276-1278

31 Ngai IM, Van Arsdale A, Govindappagari S, et al. Skin preparation for prevention of surgical site infection after cesarean delivery: a randomized controlled trial. Obstet Gynecol 2015;126(6):1251-1257

32 Tschudin-Sutter S, Frei R, Egli-Gany D, et al. No risk of surgical site infections from residual bacteria after disinfection with povidoneiodine-alcohol in 1014 cases: a prospective observational study. Ann Surg 2012;255(3):565-569

33 Cronquist AB, Jakob K, Lai L, Della Latta P, Larson EL. Relationship between skin microbial counts and surgical site infection after neurosurgery. Clin Infect Dis 2001;33(8):1302-1308

34 Davies BM, Patel HC. Letter to the editor: is a reduced duration of post-discharge surgical site infection surveillance really in our best interests? Euro Surveill 2015;20(13):42

35 O'Shaughnessy M, O'Malley VP, Corbett G, Given HF. Optimum duration of surgical scrub-time. Br J Surg 1991;78(6):685-686

36 Morrison TN, Chen AF, Taneja M, Küçükdurmaz F, Rothman RH, Parvizi J. Single vs repeat surgical skin preparations for reducing surgical site infection after total joint arthroplasty: a prospective, randomized, double-blinded study. J Arthroplasty 2016;31; (6):1289-1294

37 Davies BM, Patel HC. Does chlorhexidine and povidone-iodine preoperative antisepsis reduce surgical site infection in cranial neurosurgery? Ann R Coll Surg Engl 2016;98(6):405-408

38 Durani P, Leaper D. Povidone-iodine: use in hand disinfection, skin preparation and antiseptic irrigation. Int Wound J 2008;5; (3):376-387 